\title{
Differences in Abdominal Body Composition According to Glycemic Status: An Inverse Probability Treatment Weighting Analysis
}

\author{
Seungbong Han ${ }^{1}$, Young-Jee Jeon², Gyung-Min Park ${ }^{3}$, Tae Young Lee ${ }^{4}$, Soon Eun Park ${ }^{5}$, Gyeongseok Yu \\ Byung Ju Kang ${ }^{3}$ \\ ${ }^{1}$ Department of Biostatistics, Korea University College of Medicine, Seoul; Departments of ${ }^{2}$ Family Medicine, ${ }^{3}$ Internal \\ Medicine, ${ }^{4}$ Radiology, ${ }^{5}$ Anesthesiology and Pain Medicine, Ulsan University Hospital, University of Ulsan College of \\ Medicine, Ulsan, Korea
}

Background: Several studies have reported that abdominal fat and muscle changes occur in diabetic patients. However, there are few studies about such changes among prediabetic patients. In this study, we evaluated the differences in abdominal fat and muscles based on abdominopelvic computed tomography in prediabetic and diabetic subjects compared to normal subjects.

Methods: We performed a cross-sectional study using health examination data from March 2014 to June 2019 at Ulsan University Hospital and classified subjects into normal, prediabetic, and diabetic groups. We analyzed the body mass index corrected area of intra-abdominal components among the three groups using inverse probability treatment weighting (IPTW) analysis.

Results: Overall, 8,030 subjects were enrolled; 5,137 (64.0\%), 2,364 (29.4\%), and 529 (6.6\%) subjects were included in the normal, prediabetic, and diabetic groups, respectively. After IPTW adjustment of baseline characteristics, there were significant differences in log visceral adipose tissue index (VATI; $1.22 \pm 0.64 \mathrm{~cm}^{2} /\left[\mathrm{kg} / \mathrm{m}^{2}\right]$ vs. $1.30 \pm 0.63 \mathrm{~cm}^{2} /\left[\mathrm{kg} / \mathrm{m}^{2}\right]$ vs. $1.47 \pm 0.64 \mathrm{~cm}^{2} /\left[\mathrm{kg} / \mathrm{m}^{2}\right], P<0.001$ ) and low-attenuation muscle index (LAMI; $1.02 \pm 0.36 \mathrm{~cm}^{2} /\left[\mathrm{kg} / \mathrm{m}^{2}\right]$ vs. $1.03 \pm 0.36 \mathrm{~cm}^{2} /\left[\mathrm{kg} / \mathrm{m}^{2}\right]$ vs. $1.09 \pm 0.36 \mathrm{~cm}^{2} /\left[\mathrm{kg} / \mathrm{m}^{2}\right]$, $P<0.001$ ) among the normal, prediabetic, and diabetic groups. Prediabetic subjects had higher log VATI (estimated coefficient $=0.082, P<0.001$ ), and diabetic subjects had higher $\log$ VATI (estimated coefficient $=0.248, P<0.001$ ) and LAMI (estimated coefficient $=0.078, P<0.001$ ) compared to normal subjects.

Conclusion: Considering that VATI and LAMI represented visceral fat and lipid-rich skeletal muscle volumes, respectively, visceral obesity was identified in both prediabetic and diabetic subjects compared to normal subjects in this study. However, intra-muscular fat infiltration was observed in diabetic subjects only.

Keywords: Abdominal fat; Abdominal muscles; Prediabetic state; Diabetes mellitus

\section{INTRODUCTION}

Diabetes is a major global health problem. It is associated with Received: 30 April 2021, Revised: 22 June 2021, Accepted: 7 July 2021

Corresponding author: Byung Ju Kang

Department of Internal Medicine, Ulsan University Hospital, University of Ulsan College of Medicine, 877 Bangeojinsunhwan-doro, Dong-gu, Ulsan 44033, Korea

Tel: +82-52-250-8870, Fax: +82-52-250-8997, E-mail: pastnumber@naver.com

an elevated risk of obesity, cardiovascular morbidity and mortality [1-4]. Several studies have reported that adipose tissue and muscle changes occur in diabetic patients [5-7]. The increase in

Copyright $\left({ }_{0} 2021\right.$ Korean Endocrine Society

This is an Open Access article distributed under the terms of the Creative Commons Attribution Non-Commercial License (https://creativecommons.org/ licenses/by-nc/4.0/) which permits unrestricted non-commercial use, distribution, and reproduction in any medium, provided the original work is properly cited. 
visceral adipose tissue (VAT) is associated with insulin resistance and a higher prevalence of diabetes [8-10]. Additionally, decreased muscle mass and lipid-rich skeletal muscle are associated with a risk of incident diabetes $[11,12]$. However, few studies have evaluated the relationship between abdominal body composition and glycemic control status, including prediabetes.

Simple measurement values such as body weight, waist circumference, and body mass index (BMI) do not accurately represent abdominal body fat and muscle compositions [13]. Computed tomography (CT) is a useful tool for assessing body fat and muscle distributions; they can be accurately visualized based on CT attenuation values [14]. Thus, this study aimed to evaluate differences in abdominal fat and muscles based on abdominopelvic computed tomography (APCT) measurements in prediabetic and diabetic subjects compared to normal subjects from a large cohort who voluntarily underwent health examinations.

\section{METHODS}

\section{Study design and subjects}

We performed a retrospective cross-sectional study using health examination data from subjects greater than 19 years of age who underwent self-referred APCT as part of routine checkups at the Health Promotion Center in Ulsan University Hospital, in Ulsan, Korea, from March 2014 to June 2019. If the subjects had undergone multiple checkups, we only collected data from the first health examination data as the index. Additionally, subjects were excluded if they had missing baseline characteristics such as smoking, alcohol consumption, height, weight, and waist circumference. We classified the subjects into non-diabetic and diabetic subjects on the basis of their self-report questionnaires. Glycosylated hemoglobin ( $\mathrm{HbA1c}$ ) and fasting plasma glucose (FPG) were further evaluated to identify and then exclude subjects who were potentially misdiagnosed. Additionally, non-diabetic subjects were further classified into normal and prediabetic groups based on their HbA1c and FPG results. Consequently, we classified the enrolled subjects into three groups: normal, prediabetic, and diabetic groups (Fig. 1). This study was approved by the local Institutional Review Board of the Ulsan University Hospital (No. 2021-01-036) and abided by the principles outlined in the Declaration of Helsinki. Due to the retrospective nature and the anonymization of the data included in the study, the need for informed consent was waived.

\section{Definitions}

We defined prediabetes and diabetes based on the definition

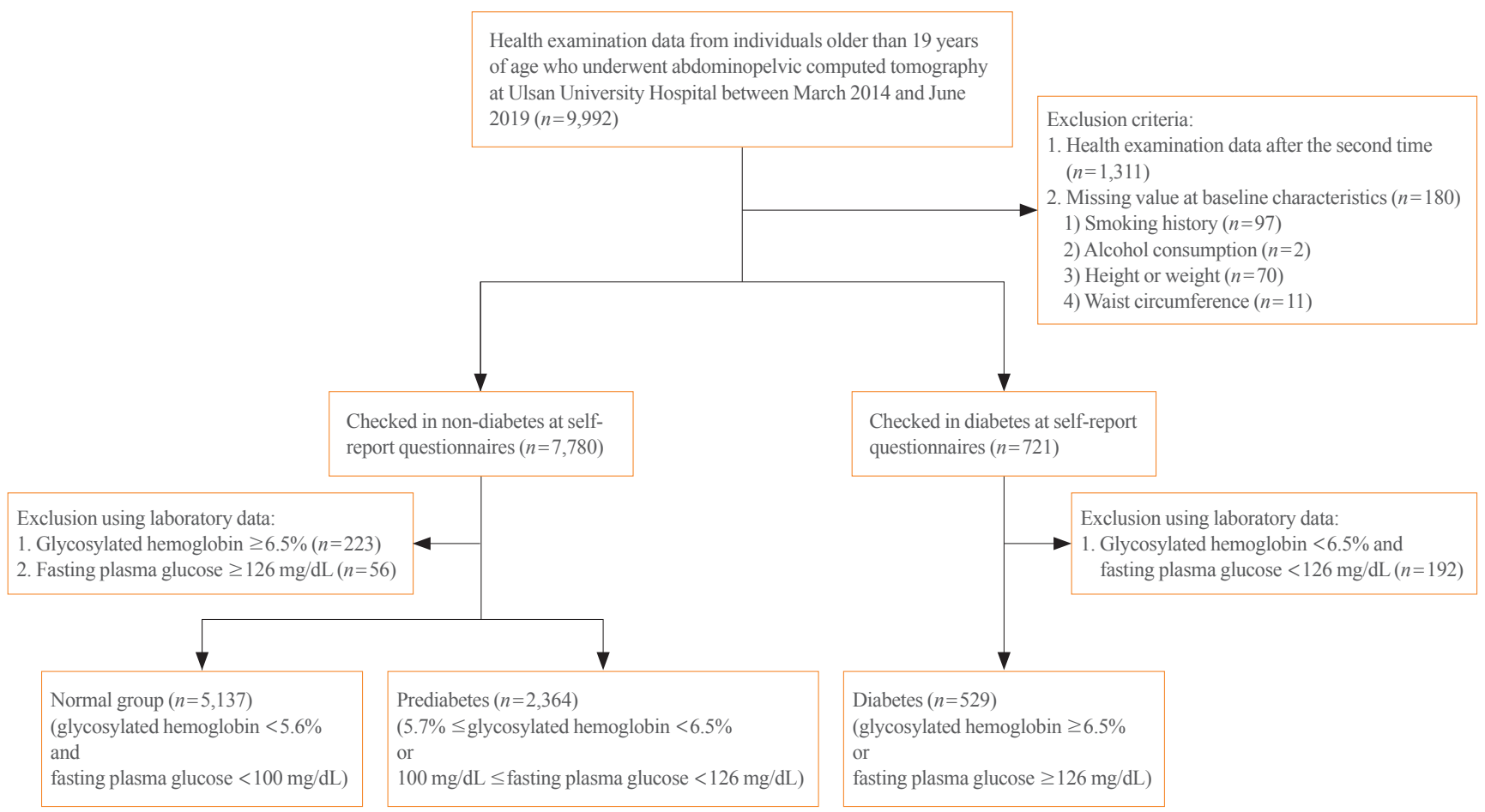

Fig. 1. Classification of subjects based on self-report questionnaires and laboratory results with respect to glycosylated hemoglobin and fasting plasma glucose. 
recommended by the American Diabetes Association [15]. Subjects were classified as having diabetes if they self-reported having diabetes in the questionnaires and if they had laboratory results suggestive of diabetes (HbAlc $\geq 6.5 \%$ or FPG $\geq 126$ $\mathrm{mg} / \mathrm{dL}$ ). Subjects were classified as having prediabetes if they self-reported that they did not have diabetes in the questionnaires and if they had laboratory results suggestive of prediabetes $(5.7 \% \leq \mathrm{HbA} 1 \mathrm{c}<6.5 \%$ or $100 \mathrm{mg} / \mathrm{dL} \leq \mathrm{FPG}<126 \mathrm{mg} / \mathrm{dL})$. Finally, subjects were classified as being normal if they self-reported that they did not have diabetes in the questionnaires and if they had laboratory results within the normal range (HbA1c $<5.7 \%$ and $\mathrm{FPG}<100 \mathrm{mg} / \mathrm{dL}$ ).

\section{Clinical and laboratory measurements}

All clinical and laboratory data were gathered from the clinical data warehouse software linked to the electronic medical records at the Ulsan University Hospital. Clinical information such as age, sex, smoking, drinking, exercise habits, and comorbidities, including cardiovascular disease, hypertension, and hyperlipidemia, was collected using a standardized self-report questionnaire issued before the check-up. The subjects' height and weight were measured without shoes and heavy clothing; these values were also used to calculate the subject's BMI. The waist circumference was measured at the end of normal expiration in the mid-point between the anterior superior iliac crest and lowest rib. Systolic and diastolic blood pressures were measured using an automatic manometer that was placed on the right arm while subjects were in the sitting position in a relaxed state. A venous blood sample was drawn from the antecubital vein after overnight fasting and subsequently analyzed in the central and certified laboratory of the Ulsan University Hospital. Laboratory information obtained included total cholesterol, triglyceride, high-density lipoprotein cholesterol (HDL-C), low-density lipoprotein cholesterol (LDL-C), HbA1c, and FPG levels.

\section{APCT and body composition analysis}

All study subjects underwent APCT using the SOMATOM Definition FLASH CT scanner (Siemens Healthcare, Erlangen, Germany). All subjects were applied to the following protocol: $100 \mathrm{kV}$ peak, $180 \mathrm{~mA}$, and 3-mm slice thickness at expiration and at the breath-hold state. Contrast-enhanced CT images were obtained 80 seconds after $150 \mathrm{~mL}$ of contrast material (Xenetix 350, Guerbet, Roissy, France) was administered using an automatic power injector. Two consecutive axial APCT images at the inferior endplate level of the third lumbar vertebra were assessed and averaged for each individual to determine abdominal body composition. Abdominal body composition was analyzed using the Asan-J software (Asan Medical Center, Seoul, Korea) as it has been found to exhibit high performance and accuracy in the abdominal composition analysis using CT images [16,17].

Several studies have reported that VAT is associated with insulin resistance, and subcutaneous adipose tissue (SAT) has the opposite effect for insulin resistance [8-10,18]. VAT is localized fat around the internal organs, and SAT is defined as the fat beneath the skin $[19,20]$. We outlined and measured total abdominal fat (TAF) based on the threshold of -190 to -30 Hounsfield units (HU), and divided TAF into VAT and SAT based on anatomical distributions of the APCT images [17,21].

Increases in intramuscular fat infiltration are strongly associated with insulin resistance by reducing the glucose uptake of skeletal muscles [22]. Low-attenuation muscle (LAM) indicates lipid-rich skeletal muscle, which containes more fat elements between and inside the muscle fibers, and conversely normalattenuation muscle (NAM) represents lipid-poor skeletal muscle, which includes less fat elements between and inside the muscle fibers [23]. These findings suggest that LAM and NAM represent low and good quality muscles on insulin sensitivity, respectively. We identified and quantified total abdominal muscle (TAM) based on the threshold of -29 to $150 \mathrm{HU}$, and divided TAM into LAM ( -29 to $29 \mathrm{HU}$ ) and NAM (30 to $150 \mathrm{HU}$ ) according to muscle attenuation value of APCT images [24,25].

Thereafter, we corrected the cross-sectional areas of the abdominal fat and muscles by BMI based on the Foundation for the National Institutes of Health Sarcopenia Project recommendation and described them as the visceral adipose tissue index $\left(\mathrm{VATI}=\mathrm{VAT}\left[\mathrm{cm}^{2}\right] / \mathrm{BMI}\left[\mathrm{kg} / \mathrm{m}^{2}\right]\right)$, subcutaneous adipose tissue index $\left(\mathrm{SATI}=\mathrm{SAT}\left[\mathrm{cm}^{2}\right] / \mathrm{BMI}\left[\mathrm{kg} / \mathrm{m}^{2}\right]\right)$, total abdominal fat in$\operatorname{dex}\left(\mathrm{TAFI}=\mathrm{TAF}\left[\mathrm{cm}^{2}\right] / \mathrm{BMI}\left[\mathrm{kg} / \mathrm{m}^{2}\right]\right)$, low-attenuation muscle index $\left(\mathrm{LAMI}=\mathrm{LAM}\left[\mathrm{cm}^{2}\right] / \mathrm{BMI}\left[\mathrm{kg} / \mathrm{m}^{2}\right]\right)$, normal-attenuation muscle index $\left(\mathrm{NAMI}=\mathrm{NAM}\left[\mathrm{cm}^{2}\right] / \mathrm{BMI}\left[\mathrm{kg} / \mathrm{m}^{2}\right]\right)$, and total abdominal muscle index $\left(\mathrm{TAMI}=\mathrm{TAM}\left[\mathrm{cm}^{2}\right] / \mathrm{BMI}\left[\mathrm{kg} / \mathrm{m}^{2}\right]\right)$ $[5,26]$.

\section{Statistical analysis}

The subjects' clinical and demographic characteristics were summarized using means and standard deviations for continuous variables and frequencies and proportions for categorical variables. Comparisons between the clinical and demographic characteristics among the three groups (normal, prediabetic, and diabetic subjects) were also made. Some variables were severely skewed to the right; thus, we conducted log transformation to obtain more stable results for further analysis. To identify the 
associations between the study groups and abdominal body compositions, we fitted the univariate and multivariate regression models. In the multivariate models, all baseline characteristics in Table 1 (age, sex, height, weight, cardiovascular disease, hypertension, hyperlipidemia, smoking status, alcohol use, exercise frequency, systolic blood pressure, diastolic blood pressure, waist circumference, total cholesterol, log triglyceride, and $\log$ HDL-C and LDL-C levels) were adjusted for.

To reduce the impact of potential confounding effects among the three groups, we also conducted an inverse probability treat- ment weighting (IPTW) analysis. IPTW was the statistical method used to adjust for confounding due to the covariate differences between the comparator groups using the propensity score. We estimated the generalized propensity score using a multi-category generalized logistic regression model [27], and computed the inverse probability weight by using the inverse generalized propensity score. The variables that were used to derive the generalized propensity score were the factors used for adjustment in the multivariate analysis. Using this approach, the inverse probability weight assigns a weight proportional to the

Table 1. Baseline Characteristics for Subjects Who Underwent Health Examinations, Including Abdominopelvic Computed Tomography

\begin{tabular}{|c|c|c|c|c|c|c|}
\hline \multirow[b]{2}{*}{ Characteristic } & \multicolumn{3}{|c|}{ Unadjusted values } & \multicolumn{3}{|c|}{ Adjusted values by IPTW } \\
\hline & $\begin{array}{c}\text { Normal } \\
(n=5,137)\end{array}$ & $\begin{array}{c}\text { Prediabetes } \\
(n=2,364)\end{array}$ & $\begin{array}{l}\text { Diabetes } \\
(n=529)\end{array}$ & $\begin{array}{c}\text { Normal } \\
(n=5,137)\end{array}$ & $\begin{array}{c}\text { Prediabetes } \\
(n=2,364)\end{array}$ & $\begin{array}{l}\text { Diabetes } \\
(n=529)\end{array}$ \\
\hline Age, yr & $51.1 \pm 9.5$ & $55.0 \pm 8.4$ & $57.5 \pm 8.2$ & $52.7 \pm 9.8$ & $53.2 \pm 8.6$ & $54.8 \pm 8.0$ \\
\hline Male sex & $2,797(54.4)$ & $1,512(64.0)$ & $380(71.8)$ & $3,006(58.5)$ & $1,396(59.0)$ & $357(67.4)$ \\
\hline Height, $\mathrm{cm}$ & $165.5 \pm 8.7$ & $165.9 \pm 8.8$ & $165.9 \pm 9.1$ & $165.7 \pm 8.8$ & $165.6 \pm 8.6$ & $166.6 \pm 9.4$ \\
\hline Weight, kg & $64.5 \pm 11.8$ & $68.4 \pm 11.8$ & $68.1 \pm 12.1$ & $65.9 \pm 12.2$ & $66.0 \pm 11.8$ & $67.6 \pm 13.3$ \\
\hline Cardiovascular disease & $128(2.5)$ & $88(3.7)$ & $47(8.9)$ & $168(3.3)$ & $79(3.4)$ & $22(4.1)$ \\
\hline Hypertension & $690(13.4)$ & $607(25.7)$ & $219(41.4)$ & $975(19.0)$ & $469(19.9)$ & $122(23.1)$ \\
\hline Hyperlipidemia & $239(4.7)$ & $158(6.7)$ & $57(10.8)$ & $296(5.8)$ & $138(5.8)$ & $37(7.0)$ \\
\hline \multicolumn{7}{|l|}{ Smoking history } \\
\hline Non-smoker & $2,925(56.9)$ & $1,112(47.0)$ & $203(38.4)$ & $2,709(52.7)$ & $1,235(52.2)$ & $241(45.6)$ \\
\hline Ex-smoker & $1,249(24.3)$ & $728(30.8)$ & $167(31.6)$ & $1,369(26.7)$ & $642(27.2)$ & $163(30.9)$ \\
\hline Current smoker & $963(18.7)$ & $524(22.2)$ & $159(30.1)$ & $1,059(20.6)$ & $487(20.6)$ & $125(23.6)$ \\
\hline \multicolumn{7}{|l|}{ Alcohol consumption } \\
\hline None & $1,993(38.8)$ & $864(36.5)$ & $225(42.5)$ & $1,968(38.3)$ & $914(38.7)$ & $198(37.4)$ \\
\hline 1-2/week & 2,201 (42.8) & $908(38.4)$ & $195(36.9)$ & $2,119(41.3)$ & $971(41.1)$ & $227(43.0)$ \\
\hline$\geq 3 /$ week & $943(18.4)$ & $592(25.0)$ & $109(20.6)$ & $1,050(20.4)$ & $479(20.2)$ & $104(19.7)$ \\
\hline \multicolumn{7}{|l|}{ Exercise grade } \\
\hline None & $1,899(37.0)$ & $911(38.5)$ & $211(39.9)$ & $1,926(37.5)$ & $887(37.5)$ & $198(37.4)$ \\
\hline $1-2 /$ week & $1,481(28.8)$ & $642(27.2)$ & $149(28.2)$ & $1,460(28.4)$ & $683(28.9)$ & $150(28.4)$ \\
\hline$\geq 3 /$ week & $1,757(34.2)$ & $811(34.3)$ & $169(31.9)$ & $1,751(34.1)$ & $794(33.6)$ & $186(35.2)$ \\
\hline SBP, mm Hg & $122.5 \pm 13.1$ & $126.9 \pm 12.9$ & $128.5 \pm 13.3$ & $124.1 \pm 13.4$ & $124.6 \pm 13.2$ & $125.2 \pm 13.5$ \\
\hline DBP, $\mathrm{mm} \mathrm{Hg}$ & $76.9 \pm 9.4$ & $79.9 \pm 9.2$ & $79.0 \pm 8.9$ & $77.9 \pm 9.4$ & $78.4 \pm 9.3$ & $78.5 \pm 9.4$ \\
\hline Waist circumference, $\mathrm{cm}$ & $83.4 \pm 8.0$ & $86.9 \pm 7.7$ & $87.7 \pm 8.5$ & $84.7 \pm 8.3$ & $85.0 \pm 7.9$ & $85.9 \pm 8.7$ \\
\hline Total cholesterol, mg/dL & $188.9 \pm 36.2$ & $189.2 \pm 38.4$ & $166.6 \pm 39.8$ & $187.5 \pm 36.8$ & $188.5 \pm 39.0$ & $186.6 \pm 42.6$ \\
\hline Log triglyceride, $\mathrm{mg} / \mathrm{dL}^{\mathrm{a}}$ & $4.5 \pm 0.5$ & $4.7 \pm 0.5$ & $4.7 \pm 0.6$ & $4.5 \pm 0.5$ & $4.5 \pm 0.5$ & $4.6 \pm 0.6$ \\
\hline Log HDL-C, mg/dL ${ }^{a}$ & $4.0 \pm 0.3$ & $3.9 \pm 0.3$ & $3.8 \pm 0.3$ & $4.0 \pm 0.3$ & $4.0 \pm 0.3$ & $3.9 \pm 0.3$ \\
\hline LDL-C, mg/dL & $128.1 \pm 34.2$ & $129.5 \pm 35.1$ & $108.4 \pm 35.7$ & $127.2 \pm 34.5$ & $128.3 \pm 36.0$ & $127.2 \pm 39.8$ \\
\hline
\end{tabular}

Values are expressed as mean \pm standard deviation or number (\%).

IPTW, inverse probability treatment weighting; SBP, systolic blood pressure; DBP, diastolic blood pressure; HDL-C, high-density lipoprotein cholesterol; LDL-C, low-density lipoprotein cholesterol.

${ }^{a}$ Log-transformed values were used to present the triglyceride and HDL-C distribution. 
reciprocal of the probability of being assigned to one of treatment groups to each patient. Furthermore, we stabilized it by multiplying the average generalized propensity score values by the corresponding treatment group. Based on the weights, summary statistics for the study groups were calculated to evaluate the similarity of the covariates (Table 1). All reported $P$ values are two-sided, and $P$ values $<0.05$ were considered statistically significant. R version 3.0 (http://cran.r-project.org/) software was used for statistical analyses. Specifically, the R CBPS package (R Foundation for Statistical Computing, Vienna, Austria) was used for the IPTW analyses [28].

\section{RESULTS}

\section{Baseline characteristics}

Overall, 8,030 subjects were enrolled; 5,137 (64.0\%), 2,364 (29.4\%), and $529(6.6 \%)$ subjects were included in the normal, prediabetic, and diabetic groups, respectively. Mean age of the study subjects was $52.7 \pm 9.4$ years, and 4,689 (58.4\%) subjects were male. HbAlc and FPG levels for the normal, prediabetic, and diabetic groups were $5.3 \% \pm 0.2 \%$ vs. $5.7 \% \pm 0.3 \%$ vs. $7.5 \% \pm 1.3 \%$; and $85.9 \pm 8.1 \mathrm{mg} / \mathrm{dL}$ vs. $97.7 \pm 11.5 \mathrm{mg} / \mathrm{dL}$ vs. $146.8 \pm 41.9 \mathrm{mg} / \mathrm{dL}$, respectively. Baseline characteristics before and after IPTW adjustment in each group are presented in Table 1. Subjects in the diabetic group were older (51.1 \pm 9.5 years vs. $55.0 \pm 8.4$ years vs. $57.5 \pm 8.2$ years, $P<0.001$ ), and had lower total cholesterol $(188.9 \pm 36.2 \mathrm{mg} / \mathrm{dL}$ vs. $189.2 \pm 38.4$ vs. $166.6 \pm 39.8 \mathrm{mg} / \mathrm{dL}, P<0.001)$, HDL-C $(56.3 \pm 16.1 \mathrm{mg} / \mathrm{dL}$ vs. $51.5 \pm 14.9 \mathrm{mg} / \mathrm{dL}$ vs. $48.4 \pm 14.0 \mathrm{mg} / \mathrm{dL}, P<0.001)$, and LDL-C $(128.1 \pm 34.2 \mathrm{mg} / \mathrm{dL}$ vs. $129.5 \pm 35.1 \mathrm{mg} / \mathrm{dL}$ vs. $108.4 \pm$ $35.7 \mathrm{mg} / \mathrm{dL}, P<0.001)$, and higher triglyceride $(99.4 \pm 62.1 \mathrm{mg} /$
dL vs. $121.8 \pm 76.9 \mathrm{mg} / \mathrm{dL}$ vs. $132.6 \pm 91.4 \mathrm{mg} / \mathrm{dL}, P<0.001)$ than those in the normal and prediabetic groups. Compared to normal subjects, there were linear increases in the prevalence of men $(54.4 \%$ vs. $64.0 \%$ vs. $71.8 \%, P<0.001)$, current smoking ( $18.7 \%$ vs. $22.2 \%$ vs. $30.1 \%, P<0.001)$, cardiovascular disease ( $2.5 \%$ vs. $3.7 \%$ vs. $8.9 \%, P<0.001)$, hypertension $(13.4 \%$ vs. $25.7 \%$ vs. $41.4 \%, P<0.001$ ), and hyperlipidemia ( $4.7 \%$ vs. $6.7 \%$ vs. $10.8 \%, P<0.001)$ in prediabetic and diabetic subjects.

\section{IPTW adjusted abdominal body composition results and proportional change}

IPTW adjusted abdominal fat and muscle index based on the glycemic control status are presented in Table 2 . There were significant differences in the Log VATI $\left(1.22 \pm 0.64 \mathrm{~cm}^{2} /\left[\mathrm{kg} / \mathrm{m}^{2}\right]\right.$ vs. $1.30 \pm 0.63 \mathrm{~cm}^{2} /\left[\mathrm{kg} / \mathrm{m}^{2}\right]$ vs. $1.47 \pm 0.64 \mathrm{~cm}^{2} /\left[\mathrm{kg} / \mathrm{m}^{2}\right]$, $P<0.001)$, SATI $\left(5.96 \pm 2.01 \mathrm{~cm}^{2} /\left[\mathrm{kg} / \mathrm{m}^{2}\right]\right.$ vs. $5.86 \pm 1.96 \mathrm{~cm}^{2} /$ $\left[\mathrm{kg} / \mathrm{m}^{2}\right]$ vs. $\left.5.36 \pm 2.21 \mathrm{~cm}^{2} /\left[\mathrm{kg} / \mathrm{m}^{2}\right], P<0.001\right)$, TAFI $(10.22 \pm$ $3.07 \mathrm{~cm}^{2} /\left[\mathrm{kg} / \mathrm{m}^{2}\right]$ vs. $10.41 \pm 3.08 \mathrm{~cm}^{2} /\left[\mathrm{kg} / \mathrm{m}^{2}\right]$ vs. $10.61 \pm 3.47$ $\left.\mathrm{cm}^{2} /\left[\mathrm{kg} / \mathrm{m}^{2}\right], P<0.001\right)$, LAMI $\left(1.02 \pm 0.36 \mathrm{~cm}^{2} /\left[\mathrm{kg} / \mathrm{m}^{2}\right]\right.$ vs $1.03 \pm 0.36 \mathrm{~cm}^{2} /\left[\mathrm{kg} / \mathrm{m}^{2}\right]$ vs. $\left.1.09 \pm 0.36 \mathrm{~cm}^{2} /\left[\mathrm{kg} / \mathrm{m}^{2}\right], P<0.001\right)$ and TAMI $\left(5.69 \pm 1.22 \mathrm{~cm}^{2} /\left[\mathrm{kg} / \mathrm{m}^{2}\right]\right.$ vs. $5.69 \pm 1.19 \mathrm{~cm}^{2} /\left[\mathrm{kg} / \mathrm{m}^{2}\right]$ vs. $\left.5.82 \pm 1.24 \mathrm{~cm}^{2} /\left[\mathrm{kg} / \mathrm{m}^{2}\right], P=0.022\right)$ among the normal, prediabetic, and diabetic groups.

Additionally, the area ratios for the different body compositions in normal, prediabetic, and diabetic subjects were as follows: (1) TAF to TAM were $1.84,1.87$, and 1.89; (2) VAT to TAF were $39.9 \%, 41.9 \%$, and $47.4 \%$; (3) LAM to TAM were $18.1 \%, 18.2 \%$, and $19.1 \%$, respectively. Upon analysis of the IPTW-adjusted results in a generalized linear regression model, the prediabetic subjects had an increase in the ratio of VAT to TAF (estimated coefficient, 2.147; 95\% confidence interval

Table 2. Study Outcome Comparisons for the Inverse Probability Treatment Weighted Subjects

\begin{tabular}{lcccc}
\hline Variable & Normal $(n=5,137)$ & Prediabetes $(n=2,364)$ & Diabetes $(n=529)$ & $P$ value \\
\hline Log VATI, $\mathrm{cm}^{2} /\left(\mathrm{kg} / \mathrm{m}^{2}\right)^{\mathrm{b}}$ & $1.22 \pm 0.64$ & $1.30 \pm 0.63$ & $1.47 \pm 0.64$ & $<0.001$ \\
SATI, $\mathrm{cm}^{2} /\left(\mathrm{kg} / \mathrm{m}^{2}\right)$ & $5.96 \pm 2.01$ & $5.86 \pm 1.96$ & $5.36 \pm 2.21$ & $<0.001$ \\
TAFI, $\mathrm{cm}^{2} /\left(\mathrm{kg} / \mathrm{m}^{2}\right)$ & $10.22 \pm 3.07$ & $10.41 \pm 3.08$ & $10.61 \pm 3.47$ & $<0.001$ \\
LAMI, $\mathrm{cm}^{2} /\left(\mathrm{kg} / \mathrm{m}^{2}\right)$ & $1.02 \pm 0.36$ & $1.03 \pm 0.36$ & $1.09 \pm 0.36$ & $<0.001$ \\
NAMI, $\mathrm{cm}^{2} /\left(\mathrm{kg} / \mathrm{m}^{2}\right)$ & $4.68 \pm 1.24$ & $4.67 \pm 1.21$ & $4.73 \pm 1.29$ & 0.463 \\
TAMI, $\mathrm{cm}^{2} /\left(\mathrm{kg} / \mathrm{m}^{2}\right)$ & $5.69 \pm 1.22$ & $5.69 \pm 1.19$ & $5.82 \pm 1.24$ & 0.022 \\
\hline
\end{tabular}

Values are expressed as mean \pm standard deviation.

VATI, visceral adipose tissue index; SATI, subcutaneous adipose tissue index; TAFI, total abdominal fat index; LAMI, low-attenuation muscle index; NAMI, normal-attenuation muscle index; TAMI, total abdominal muscle index.

${ }^{\text {a }}$ Statistical comparisons of the data were performed using inverse probability treatment weighting linear regression analyses; ${ }^{b}$ Log-transformed values were used to present the VATI distribution. 


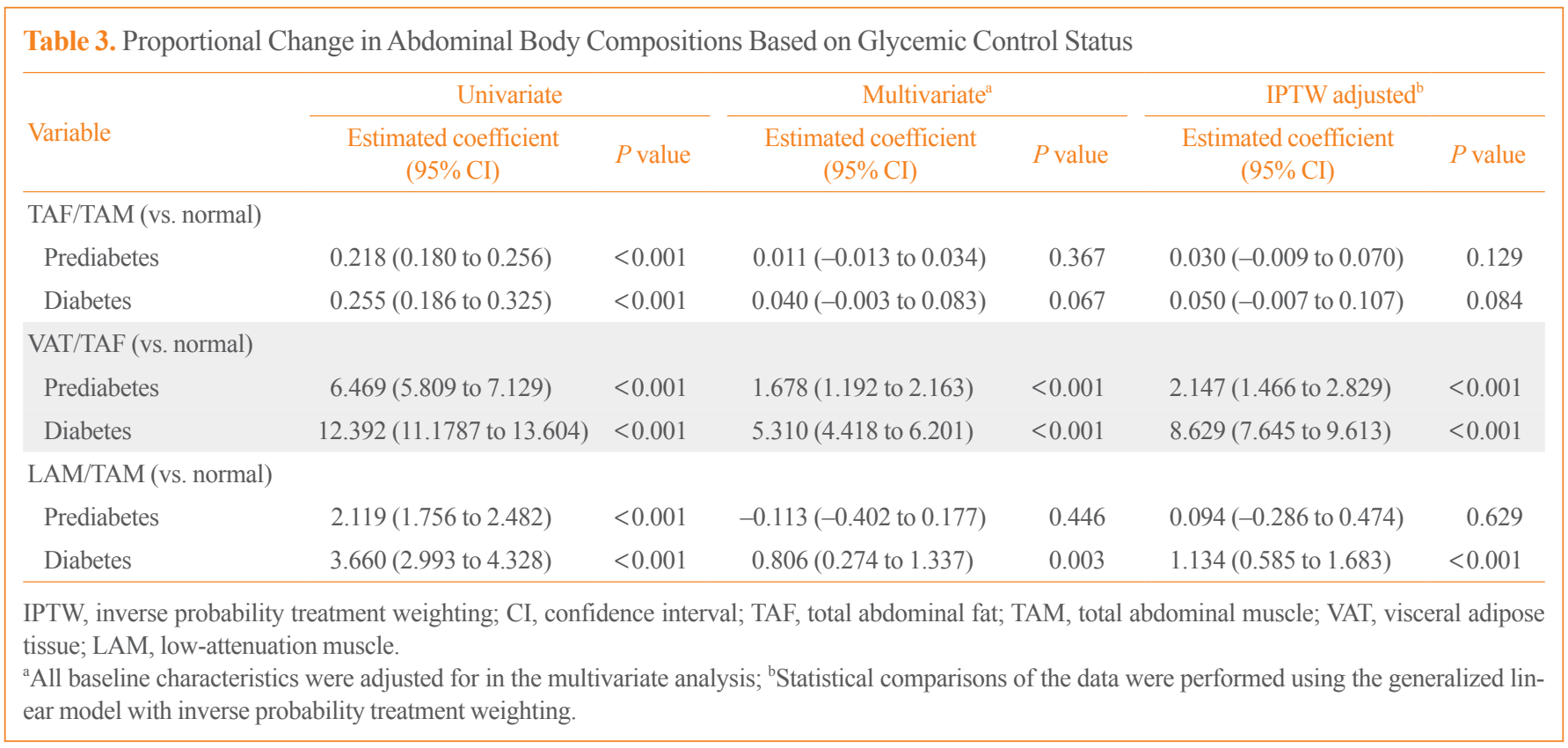

[CI], 1.466 to $2.829 ; P<0.001)$ compared to normal subjects. Additionally, diabetic subjects had an increase in the ratio of VAT to TAF $(8.629 ; 95 \% \mathrm{CI}, 7.645$ to $9.613 ; P<0.001)$ and LAM to TAM $(1.134 ; 95 \%$ CI, 0.585 to $1.683 ; P<0.001)$ compared to normal subjects (Table 3 ).

\section{Abdominal body composition results analyzed using linear regression models}

The abdominal fat and muscle index results based on the glycemic control status are shown in Table 4 for the univariate, multivariate, and IPTW adjusted analyses. Prediabetic subjects had higher Log VATI $(0.082 ; 95 \%$ CI, 0.051 to $0.114 ; P<0.001)$ and TAFI $(0.193 ; 95 \% \mathrm{CI}, 0.039$ to $0.347 ; P=0.014)$ than normal subjects in the IPTW adjusted analysis. Diabetic subjects had higher Log VATI $(0.248 ; 95 \%$ CI, 0.203 to $0.294 ; P<0.001)$, TAFI ( $0.387 ; 95 \%$ CI, 0.165 to $0.610 ; P<0.001)$, LAMI $(0.078$; 95\% CI, 0.052 to $0.104 ; P<0.001)$, and TAMI $(0.127 ; 95 \% \mathrm{CI}$, 0.041 to $0.213 ; P=0.004)$, and a lower SATI $(-0.595 ; 95 \% \mathrm{CI}$, -0.739 to $-0.451 ; P<0.001)$ than normal subjects in the IPTW adjusted analysis.

\section{DISCUSSION}

The current study evaluated abdominal fat and muscle changes in prediabetic and diabetic subjects compared to normal subjects. Prediabetic subjects had higher VATI and TAFI values than the normal subjects. Diabetic subjects had higher VATI,
TAFI, LAMI, and TAMI values and lower SATI values than the normal subjects. Since the changes in TAFI and TAMI were the net results according to changes in each abdominal fat and muscle component, we were able to determine that representative findings of abdominal body composition in diabetic subjects were increases in VATI and LAMI, and decreases in SATI. Additionally, for prediabetic subjects these were increases in VATI without changes in LAMI and SATI.

Abdominal VAT has hormonal activity that is strongly associated with insulin resistance, systemic inflammation, and hyperlipidemia $[9,10,29]$. One study found that excess VAT might be a risk factor for incident prediabetes and diabetes [8]. We found that the prevalence of abdominal VATI was also higher among our prediabetic and diabetic subjects. Interestingly, although SAT was also a component of abdominal fat, SATI was decreased in diabetic subjects compared to normal subjects in our study. Several studies have suggested that SAT has metabolically protective effects against insulin resistance [18,30,31]. We hypothesized that there was a negative relationship between SAT and insulin resistance in diabetic subjects. However, this relationship was not observed in the prediabetic subjects included in this study. This might be a result of low insulin resistance and thus inability to change the SAT in prediabetic subjects. Further, well-structured studies are required to address this question. Additionally, considering the abdominal fat changes identified in this study, the increase in TAFI among prediabetic and diabetic subjects might be attributed to the increase in VATI. 
Table 4. Relationships between Study Grouping and Abdominal Body Composition

\begin{tabular}{|c|c|c|c|c|c|c|}
\hline \multirow[b]{2}{*}{ Variable } & \multicolumn{2}{|l|}{ Univariate } & \multicolumn{2}{|l|}{ Multivariate $^{\mathrm{a}}$} & \multicolumn{2}{|l|}{ 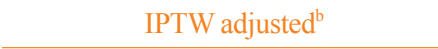 } \\
\hline & $\begin{array}{c}\text { Estimated coefficient } \\
(95 \% \mathrm{CI})\end{array}$ & $P$ value & $\begin{array}{c}\text { Estimated coefficient } \\
\qquad(95 \% \mathrm{CI})\end{array}$ & $P$ value & $\begin{array}{c}\text { Estimated coefficient } \\
(95 \% \mathrm{CI})\end{array}$ & $P$ value \\
\hline \multicolumn{7}{|c|}{ Log VATI (vs. normal) ${ }^{c}$} \\
\hline Prediabetes & $0.327(0.297$ to 0.358$)$ & $<0.001$ & $0.053(0.032$ to 0.074$)$ & $<0.001$ & $0.082(0.051$ to 0.114$)$ & $<0.001$ \\
\hline Diabetes & $0.460(0.405$ to 0.516$)$ & $<0.001$ & $0.109(0.071$ to 0.147$)$ & $<0.001$ & $0.248(0.203$ to 0.294$)$ & $<0.001$ \\
\hline \multicolumn{7}{|c|}{ SATI (vs. normal) } \\
\hline Prediabetes & $0.063(-0.035$ to 0.161$)$ & 0.207 & $-0.126(-0.197$ to -0.054$)$ & $<0.001$ & $-0.098(-0.198$ to 0.001$)$ & 0.053 \\
\hline Diabetes & $-0.503(-0.683$ to -0.324$)$ & $<0.001$ & $-0.522(-0.652$ to -0.391$)$ & $<0.001$ & $-0.595(-0.739$ to -0.451$)$ & $<0.001$ \\
\hline \multicolumn{7}{|c|}{ TAFI (vs. normal) } \\
\hline Prediabetes & 1.215 (1.067 to 1.362$)$ & $<0.001$ & $0.094(-0.001$ to 0.189$)$ & 0.052 & 0.193 (0.039 to 0.347$)$ & 0.014 \\
\hline Diabetes & $1.288(1.017$ to 1.559$)$ & $<0.001$ & $0.021(-0.153$ to 0.195$)$ & 0.813 & $0.387(0.165$ to 0.610$)$ & $<0.001$ \\
\hline \multicolumn{7}{|c|}{ LAMI (vs. normal) } \\
\hline Prediabetes & $0.121(0.103$ to 0.138$)$ & $<0.001$ & $-0.002(-0.016$ to 0.013$)$ & 0.816 & $0.009(-0.008$ to 0.027$)$ & 0.304 \\
\hline Diabetes & $0.199(0.168$ to 0.231$)$ & $<0.001$ & $0.034(0.008$ to 0.061$)$ & 0.012 & $0.078(0.052$ to 0.104$)$ & $<0.001$ \\
\hline \multicolumn{7}{|c|}{ NAMI (vs. normal) } \\
\hline Prediabetes & $-0.103(-0.163$ to -0.043$)$ & $<0.001$ & $0.010(-0.022$ to 0.042$)$ & 0.539 & $-0.008(-0.069$ to 0.053$)$ & 0.791 \\
\hline Diabetes & $-0.163(-0.273$ to -0.053$)$ & 0.004 & $-0.072(-0.131$ to -0.012$)$ & 0.018 & $0.049(-0.039$ to 0.137$)$ & 0.275 \\
\hline \multicolumn{7}{|c|}{ TAMI (vs. normal) } \\
\hline Prediabetes & $0.017(-0.042$ to 0.076$)$ & 0.564 & $0.008(-0.020$ to 0.037$)$ & 0.558 & $0.001(-0.059$ to 0.061$)$ & 0.972 \\
\hline Diabetes & $0.036(-0.072$ to 0.144$)$ & 0.512 & $-0.037(-0.089$ to 0.015$)$ & 0.158 & $0.127(0.041$ to 0.213$)$ & 0.004 \\
\hline
\end{tabular}

IPTW, inverse probability treatment weighting; CI, confidence interval; VATI, visceral adipose tissue index; SATI, subcutaneous adipose tissue index; TAFI, total abdominal fat index; LAMI, low-attenuation muscle index; NAMI, normal-attenuation muscle index; TAMI, total abdominal muscle index.

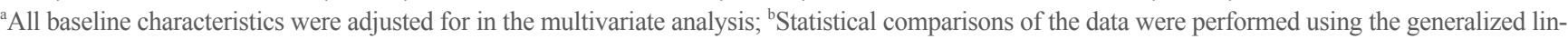
ear model with inverse probability treatment weighting; ${ }^{\circ}$ Log-transformed values were used to present the VATI distribution.

Therefore, the high ratio of VAT to TAF might be important to consider among prediabetic and diabetic subjects.

Based on the findings from previous studies, we initially hypothesized that prediabetic and diabetic subjects had increased abdominal fat and decreased abdominal muscles compared to normal subjects $[11,32]$. However, our results obtained from APCT scans showed that diabetic subjects had higher TAMI than normal subjects, and there was no significant difference in TAMI between prediabetic and normal subjects. LAMI and LAM to TAM ratio were significantly increased, but NAMI was not significantly changed in the diabetic subjects compared to the normal subjects. These changes were not observed in prediabetic subjects. One study found that higher LAM was associated with a higher prevalence of current diabetes; however, NAM was not [5]. LAM was closely related to lipid-rich skeletal muscle [23], and the ectopic skeletal muscle fat may affect the incompetence of the muscle oxidative capacity, insulin resistance, muscle frailty, and physical weakness [33-36]. These findings suggest that the abdominal component changes with increases in poor quality muscles occur in diabetic subjects, but not in prediabetic subjects.

From normal to prediabetic and diabetic subjects in our study, VATI, TFAI, LAMI, and TAMI values serially increased, and SATI values serially decreased. Although all these changes were significant in diabetic subjects, only VATI and TAFI changes were significant in prediabetic subjects. These results suggest that abdominal VAT changes might precede other abdominal fat and muscle changes when aggravating glucose intolerance, and they might be an early marker of abdominal body composition changes in prediabetic and diabetic subjects. We believe that the findings from this study are very reliable as they were derived from the areas of abdominal composition corrected for BMI. Additionally, the IPTW analysis adjusted for differences in age, sex, height, weight, underlying diseases, lifestyles, and lipid laboratory results among the three groups.

Our study had several limitations. First, since this study was 
designed as a cross-sectional study, we could not clarify the causal relationship between abdominal body composition and glycemic control status. Therefore, further prospective, large scale longitudinal studies are required to confirm the relationship over time. Second, the study was performed in a single health promotion center of the University Hospital. Additionally, the majority of our study subjects were relatively healthy. Thus, selection bias cannot be excluded. However, we tried to minimize the bias by including a relatively large sample size and by adjusting for the differences among the normal, prediabetic, and diabetic subjects using IPTW analysis. Third, since diagnosis of underlying comorbidities, including diabetes, cardiovascular disease, hypertension, and hyperlipidemia, were based on self-report questionnaires, there was a possibility of under or over diagnosis of diseases [37]. In reality, there was a mismatch between the self-report disease (more hyperlipidemia in diabetic subjects) and laboratory findings (lower total cholesterol and LDL-C in diabetic subjects). Thus, the self-reported data on comorbidities should be carefully interpreted. Fourth, we classified the study subjects into normal, prediabetic, and diabetic groups based on the findings from self-report questionnaires and laboratory $\mathrm{HbA} 1 \mathrm{c}$ and FPG results. Due to strict classification criteria, subjects might have been excluded from the appropriate study group (i.e., transient hyperglycemic subjects might have been excluded from the normal group and diabetic subjects with good glycemic control might have been excluded from the diabetic group). Fifth, we could not evaluate the subjects' medications (such as lipid lowering medications, diabetic medications, or steroids), and the presence of neuromuscular diseases or systemic inflammatory conditions affecting the subject's laboratory findings and abdominal body compositions [25]. However, because we enrolled a relatively large number of subjects and adjusted for the baseline characteristics, this should not have had a large impact on our study findings. Finally, we could not investigate abdominal fat and muscle composition differences based on the diabetic phenotype, such as type 1 or 2 diabetes. Further well-structured studies enrolling a large number of participants are required to address this question.

In conclusion, our study identified abdominal composition changes in prediabetic and diabetic subjects compared to normal subjects. Visceral obesity and poor quality muscles were increased, and SAT was decreased in diabetic subjects. However, unlike the diabetic subjects, prediabetic subjects only had increases in visceral obesity; there were no significant changes in poor quality muscles and SAT among prediabetic subjects.
These results suggest that increases in visceral adiposity are an early finding, and poor quality muscle increase and SAT decrease were late findings in subjects with poor glycemic control. Further well-structured studies, including large numbers of participants, are required to validate these results.

\section{CONFLICTS OF INTEREST}

No potential conflict of interest relevant to this article was reported.

\section{ACKNOWLEDGMENTS}

This research was supported by a grant of the Medical datadriven hospital support project, through the Korea Health Information Service (KHIS), funded by the Ministry of Health \& Welfare, Republic of Korea.

Clinical and laboratory variables were collected from the clinical data warehouse platform (Ulsan University Hospital Information of Clinical Ecosystem [uICE]) by the Medical Information Center of the Ulsan University Hospital.

\section{AUTHOR CONTRIBUTIONS}

Conception or design: S.E.P., G.Y., B.J.K. Acquisition, analysis, or interpretation of data: S.H., Y.J.J., G.M.P., T.Y.L., B.J.K. Drafting the work or revising: S.H., Y.J.J., G.M.P., T.Y.L., S.E.P., G.Y., B.J.K. Final approval of the manuscript: S.H., Y. J.J., G.M.P., T.Y.L., S.E.P., G.Y., B.J.K.

\section{ORCID}

Seungbong Han https://orcid.org/0000-0003-2938-8072

Byung Ju Kang https://orcid.org/0000-0002-1396-7398

\section{REFERENCES}

1. Rao Kondapally Seshasai S, Kaptoge S, Thompson A, Di Angelantonio E, Gao P, Sarwar N, et al. Diabetes mellitus, fasting glucose, and risk of cause-specific death. N Engl J Med 2011;364:829-41.

2. Lloyd-Jones DM, Hong Y, Labarthe D, Mozaffarian D, Appel LJ, Van Horn L, et al. Defining and setting national goals for cardiovascular health promotion and disease reduction: the American Heart Association's strategic Impact Goal through 2020 and beyond. Circulation 2010;121:586-613. 
3. Flint AJ, Hu FB, Glynn RJ, Caspard H, Manson JE, Willett WC, et al. Excess weight and the risk of incident coronary heart disease among men and women. Obesity (Silver Spring) 2010;18:377-83.

4. Abdullah A, Peeters A, de Courten M, Stoelwinder J. The magnitude of association between overweight and obesity and the risk of diabetes: a meta-analysis of prospective cohort studies. Diabetes Res Clin Pract 2010;89:309-19.

5. Tanaka M, Okada H, Hashimoto Y, Kumagai M, Nishimura H, Fukui M. Low-attenuation muscle is a predictor of diabetes mellitus: a population-based cohort study. Nutrition 2020; 74:110752.

6. Dube MC, Joanisse DR, Prud'homme D, Lemieux S, Bouchard C, Perusse L, et al. Muscle adiposity and body fat distribution in type 1 and type 2 diabetes: varying relationships according to diabetes type. Int J Obes (Lond) 2006;30: 1721-8.

7. Martin M, Almeras N, Despres JP, Coxson HO, Washko GR, Vivodtzev I, et al. Ectopic fat accumulation in patients with COPD: an ECLIPSE substudy. Int J Chron Obstruct Pulmon Dis 2017;12:451-60.

8. Neeland IJ, Turer AT, Ayers CR, Powell-Wiley TM, Vega GL, Farzaneh-Far R, et al. Dysfunctional adiposity and the risk of prediabetes and type 2 diabetes in obese adults. JAMA 2012;308:1150-9.

9. Zhang M, Hu T, Zhang S, Zhou L. Associations of different adipose tissue depots with insulin resistance: a systematic review and meta-analysis of observational studies. Sci Rep 2015;5:18495.

10. Lopes HF, Correa-Giannella ML, Consolim-Colombo FM, Egan BM. Visceral adiposity syndrome. Diabetol Metab Syndr 2016;8:40.

11. Larsen BA, Wassel CL, Kritchevsky SB, Strotmeyer ES, Criqui MH, Kanaya AM, et al. Association of muscle mass, area, and strength with incident diabetes in older adults: the Health ABC Study. J Clin Endocrinol Metab 2016;101: 1847-55.

12. Goodpaster BH, Thaete FL, Kelley DE. Thigh adipose tissue distribution is associated with insulin resistance in obesity and in type 2 diabetes mellitus. Am J Clin Nutr 2000;71: 885-92.

13. Chait A, den Hartigh LJ. Adipose tissue distribution, inflammation and its metabolic consequences, including diabetes and cardiovascular disease. Front Cardiovasc Med 2020;7: 22.

14. Haggmark T, Jansson E, Svane B. Cross-sectional area of the thigh muscle in man measured by computed tomography. Scand J Clin Lab Invest 1978;38:355-60.

15. American Diabetes Association. 2. Classification and diagnosis of diabetes: standards of medical care in diabetes-2020. Diabetes Care 2020;43(Suppl 1):S14-31.

16. Lee K, Shin Y, Huh J, Sung YS, Lee IS, Yoon KH, et al. Recent issues on body composition imaging for sarcopenia evaluation. Korean J Radiol 2019;20:205-17.

17. Park HJ, Shin Y, Park J, Kim H, Lee IS, Seo DW, et al. Development and validation of a deep learning system for segmentation of abdominal muscle and fat on computed tomography. Korean J Radiol 2020;21:88-100.

18. McLaughlin T, Lamendola C, Liu A, Abbasi F. Preferential fat deposition in subcutaneous versus visceral depots is associated with insulin sensitivity. J Clin Endocrinol Metab 2011;96:E1756-60.

19. Mittal B. Subcutaneous adipose tissue \& visceral adipose tissue. Indian J Med Res 2019;149:571-3.

20. Wajchenberg BL. Subcutaneous and visceral adipose tissue: their relation to the metabolic syndrome. Endocr Rev 2000; 21:697-738.

21. Maddocks M, Shrikrishna D, Vitoriano S, Natanek SA, Tanner RJ, Hart N, et al. Skeletal muscle adiposity is associated with physical activity, exercise capacity and fibre shift in COPD. Eur Respir J 2014;44:1188-98.

22. Virkamaki A, Korsheninnikova E, Seppala-Lindroos A, Vehkavaara S, Goto T, Halavaara J, et al. Intramyocellular lipid is associated with resistance to in vivo insulin actions on glucose uptake, antilipolysis, and early insulin signaling pathways in human skeletal muscle. Diabetes 2001;50:2337-43.

23. Kim D, Nam S, Ahn C, Kim K, Yoon S, Kim J, et al. Correlation between midthigh low-density muscle and insulin resistance in obese nondiabetic patients in Korea. Diabetes Care 2003;26:1825-30.

24. Mitsiopoulos N, Baumgartner RN, Heymsfield SB, Lyons W, Gallagher D, Ross R. Cadaver validation of skeletal muscle measurement by magnetic resonance imaging and computerized tomography. J Appl Physiol (1985) 1998;85: 115-22.

25. Aubrey J, Esfandiari N, Baracos VE, Buteau FA, Frenette J, Putman CT, et al. Measurement of skeletal muscle radiation attenuation and basis of its biological variation. Acta Physiol (Oxf) 2014;210:489-97.

26. Studenski SA, Peters KW, Alley DE, Cawthon PM, McLean RR, Harris TB, et al. The FNIH sarcopenia project: rationale, study description, conference recommendations, and 
final estimates. J Gerontol A Biol Sci Med Sci 2014;69:54758.

27. Imai K, Ratkovic M. Covariate balancing propensity score. J R Stat Soc Series B Stat Methodol 2014;76:243-63.

28. Fong C, Ratkovic M, Hazlett C, Imai K. CBPS: covariate balancing propensity score [R package version 0.21 ] [Internet]. Vienna (AT): Comprehensive R Archive Network (CRAN), 2014 [cited 2021 Jul 21]. Available from: https:// CRAN.R-project.org/package $=$ CBPS.

29. Bjorntorp P. "Portal" adipose tissue as a generator of risk factors for cardiovascular disease and diabetes. Arteriosclerosis 1990; 10:493-6.

30. Manolopoulos KN, Karpe F, Frayn KN. Gluteofemoral body fat as a determinant of metabolic health. Int $\mathrm{J}$ Obes (Lond) 2010;34:949-59.

31. Tchkonia T, Thomou T, Zhu Y, Karagiannides I, Pothoulakis $\mathrm{C}$, Jensen MD, et al. Mechanisms and metabolic implications of regional differences among fat depots. Cell Metab 2013;17:644-56.

32. Goodpaster BH, Thaete FL, Simoneau JA, Kelley DE. Subcutaneous abdominal fat and thigh muscle composition predict insulin sensitivity independently of visceral fat. Diabetes $1997 ; 46: 1579-85$.
33. Borkan GA, Hults DE, Gerzof SG, Robbins AH, Silbert CK. Age changes in body composition revealed by computed tomography. J Gerontol 1983;38:673-7.

34. Simoneau JA, Colberg SR, Thaete FL, Kelley DE. Skeletal muscle glycolytic and oxidative enzyme capacities are determinants of insulin sensitivity and muscle composition in obese women. FASEB J 1995;9:273-8.

35. Visser M, Kritchevsky SB, Goodpaster BH, Newman AB, Nevitt M, Stamm E, et al. Leg muscle mass and composition in relation to lower extremity performance in men and women aged 70 to 79: the health, aging and body composition study. J Am Geriatr Soc 2002;50:897-904.

36. Lang T, Cauley JA, Tylavsky F, Bauer D, Cummings S, Harris $\mathrm{TB}$, et al. Computed tomographic measurements of thigh muscle cross-sectional area and attenuation coefficient predict hip fracture: the health, aging, and body composition study. J Bone Miner Res 2010;25:513-9.

37. Violan C, Foguet-Boreu Q, Hermosilla-Perez E, Valderas JM, Bolibar B, Fabregas-Escurriola M, et al. Comparison of the information provided by electronic health records data and a population health survey to estimate prevalence of selected health conditions and multimorbidity. BMC Public Health 2013;13:251. 